\title{
A Planetary Health Perspective to Decarbonising Public Hospitals in Ireland: A Health Policy Report
}

\author{
Aoife Kirk ${ }^{1,2 *}$, Pippa Grenfell ${ }^{1}$, Peninah Murage ${ }^{1}$
}

\author{
${ }^{1}$ London School of Hygiene Tropical Medicine, UNITED KINGDOM \\ ${ }^{2}$ Royal College of Surgeons REPUBLIC OF IRELAND \\ *Corresponding Author: kirkaoife@gmail.com
}

Citation: Kirk, A., Grenfell, P. and Murage, P. (2021). A Planetary Health Perspective to Decarbonising Public Hospitals in Ireland: A Health Policy Report. European Journal of Environment and Public Health, 5(2), em0067. https://doi.org/10.21601/ejeph/9368

ARTICLE INFO

Received: 24 Jun. 2020

Accepted: 6 Oct. 2020

\begin{abstract}
Background: Decarbonisation refers to the process by which countries, individuals or other entities aim to achieve zero fossil carbon emissions through reduction of greenhouse gas (GHG) emissions, including procurement, energy and buildings, pharmaceuticals, transport, and waste which impacts public health. Preliminary findings on decarbonisation in healthcare systems suggest that further research is required.
\end{abstract}

Aims: This research was undertaken to explore the opportunities and barriers of decarbonisation of public hospitals within the 'climate health' planetary health boundary in the Republic of Ireland.

Methodology: A literature review was used in conjunction with semi-structured qualitative interviews to explore barriers and opportunities of decarbonisation of Irish healthcare sector. The purposive sampling for the qualitative interviews resulted in the selection of five key decision-makers within cross-sector fields including environmental, public health, management and transport.

Results: Themes emerged which reflected the cross-cutting planetary health principle. Barriers such as financial incentives and the requirement for a transdisciplinary approach were raised. The need for preparing the healthcare sector through adaptation and mitigation of the effects of climate change was also highlighted, as was the importance of leadership within the hospital from all sectors.

Recommendations: The findings emerging from this novel research through a planetary health lens can be used to further inform the 'Climate Action Plan' in the Republic of Ireland, with adaption to other healthcare sectors internationally, in order to ensure investment within the health sector in preparation for climate change.

Keywords: planetary health, public health, decarbonisation, hospitals, climate change, health policy, Ireland

\section{INTRODUCTION}

Climate change is one of the greatest global health threats of the 21st century (Watts et al., 2018; World Health Organization, 2018) with international scientific agreement that humans are contributing to the rise of emission of greenhouse gases which contribute to this global environmental public health issue (IPCC, 2018). The impact of humankind on the environment have become so profound since the Industrial Era which has resulted in a new term coined by researchers as the 'Anthropocene Era' (Whitmee et al., 2015). This new epoch has resulted in pushing the Earth into a less biologically diverse state, with significant climate change effects (Costello et al., 2009; Will Steffen, 2007). This has become a central issue on policymakers' agendas (IPCC, 2019; Masli et al., 2015).

'Decarbonisation' refers to the Intergovernmental Panel on Climate Change (IPCC) definition of the process by which countries, individuals or other entities aim to achieve zero fossil carbon emissions through reduction of greenhouse gas (GHG) emissions (IPCC, 2018). GHGs consist of a wide range of gases including carbon dioxide $\left(\mathrm{CO}_{2}\right)$, methane $\left(\mathrm{CH}_{4}\right)$ and nitrous oxide $\left(\mathrm{N}_{2} \mathrm{O}\right)$ and other heat-trapping gases. Decarbonisation within the health sector includes GHGproducing activities such as procurement, energy and buildings, pharmaceuticals, transport, waste and the manufacture, disposal and recycling of products and vehicles used in hospitals (Health Care Without Harm, 2016; Tomson, 2015).

A continuing rise of GHGs will cause significant alterations to national and international levels, considered by the UK and Republic of Ireland governments in 2019 as a 'climate emergency’ (Cunningham, 2019; Guniea, 2019). The European Union (E.U.) target states that GHG emissions should be below $20 \%$ by 2020 compared to 1990 levels. Ireland is currently predicted to achieve a $6 \%$ reduction by 2020 at most (Agency, 2019), and will therefore fail to meet the targets set under the 
2015 legally-binding Paris Agreement (Horowitz, 2016). This represents a significant shortfall and will therefore incur a large fine imposed by the E.U. (Kelly de Bruin, 2018). A radical change in Ireland's energy, agricultural and public services systems will be needed to meet the low-carbon required targets as outlined by the E.U. requirements. In 2019, Ireland was ranked by the Climate Change Performance Index (CCPI) as the worst - performing EU country (Burck, et al., 2019).

Within the health sector, the World Bank report predicted that health services in some developed countries are responsible for between $5 \%$ - $15 \%$ of national carbon emissions (World Bank, 2017). The health sectors of the United States, England, Australia, Canada and England combined release 748 million tonnes of $\mathrm{CO} 2$ equivalents annually (Health Care Without Harm, 2016). The health risks of climate change and co-benefits of climate action have been well documented in the literature (Costello, et al., 2009; Organization, 2018). However, there is little documentation and monitoring of the decarbonisation of the health sector, which contributes a significant source of GHG and carbon emissions (Health Care Without Harm, 2016).

Planetary Health $(\mathrm{PH})$ is a transdisciplinary approach which aims to examine the links between human-driven changes to the planet and their consequences, and develop appropriate solutions to the challenges identified (Stone, et al., 2018). The PH approach to health and well-being offers a strong focus on the increasingly short time-frame and urgency in which humanity and policy-makers need to address the environmental changes that affect human health (Foster et al., 2018; Stone et al., 2018).

This study aims to examine the opportunities and barriers of decarbonisation of public hospitals within the 'climate health' planetary in the Republic of Ireland, with recommendations for action following an analysis of the literature review and five semi-structured qualitative expert interviews. This research aims to further inform the 'Climate Action Plan' produced by the Irish Government to aid the scaling-up of efforts within the hospital sector towards decarbonisation in order to achieve the ambitious EU targets.

\section{METHODOLOGY}

\section{Literature Review}

The search strategy for the literature review used five electronic databases including SCOPUS, OVID Medline, OpenGrey, Sustainable Energy Authority of Ireland and Web of Science and grey literature sources including current and previous policy reports. This was used to inform the development of the Interview Guide. A word search was carried out within the databases between May 2019 and August 2019 using the key words and phrases: decarbonisation, (OR) carbon sink (OR) health care (OR) planetary health. The inclusion criteria was based upon a ten-year timeframe from 1999 to 2019. Only literature in the medium of English was reviewed.

\section{Qualitative Interviews}

Semi-structured interviews were undertaken with five candidates who were purposively selected based on the
Table 1. Interview Participants \& Roles

\begin{tabular}{cc}
\hline Public Health Specialist & Doctor \\
\hline Transport Planner & National Transport Authority \\
\hline Policy Advisor & National Sustainability Office \\
\hline Sustainability Officer & Public Hospital Sector \\
\hline $\begin{array}{c}\text { Environment / Development } \\
\text { Consultant }\end{array}$ & Non-Governmental \\
Organisation
\end{tabular}

'transdisciplinary' planetary health principles, with the inclusion of experts and/or decision-makers spanning different disciplines across Ireland. The participants were originally identified through purposive sampling through the researcher's own network. Following that, a 'snowball' sample method (Naderifar et al., 2017) was employed whereby the participants recommended other experts within their own network, thus facilitating a transdisciplinary perspective. Due to time restrictions of the Masters programme, a total of five interviews were conducted, which ranged in length from 20 to 48 minutes. Five participants representing the stakeholders agreed to be interviewed, as outlined in Table 1 .

\section{Ethics}

Full ethical approval was obtained from London School of Hygiene and Tropical Medicine. Potential participants were invited to participate through email with a written Information Sheet and Consent Form prior to undertaking the interviews with an assurance of confidentiality.

\section{Confidentiality and Data Protection}

Each participant's interview was recorded using a password-protected audio recording device. The recordings were transferred to a password-secured encrypted folder on a personal computer and transcribed to electronic format via Microsoft Word. The transcriptions were anonymised and cleaned of identifiable names. All data was stored in compliance with EU General Data Protection Regulations (Union, 2016).

\section{Data Collection and Data Analysis}

An Interview Guide was developed which was based on the initial literature scope. Data analysis was conducted on an individual case basis, with further analysis across transcripts to identify emerging themes. Following the transcription, a process of thematic analysis was undertaken, which included -

1. Multiple readings and note taking

2. Identifying emergent themes

3. Clustering of themes through a traditional cut and paste approach

4. Identifying master themes through an overarching theme table using the PH Principles as a framework

5. Coding, Analysis and Confidentiality

\section{RESULTS}

A limited amount of literature addressing the research question was obtained. While there are a large number of studies examining the health co-benefits of decarbonisation on energy efficiency, there was very limited information on the 
scope of interest regarding the healthcare sector's carbon footprint, in particular in Ireland (World Bank, 2017). Hence, there is a need for further research within this area.

According to the Environmental Protection Agency (EPA), Ireland's total national GHG emissions were just over 60 million tonnes of CO2-eq in 2017, which is $9.6 \%$ higher than 1990 emission levels (Agency, 2019; Assembly, 2018). This increase comprises of a $6.7 \%$ increase in emissions from Commercial and Public Services in 2017, including the public hospital sector in Ireland (Desmond, et al., 2014).

Hospital infrastructures have complex organisational processes and systems which both contribute as carbon polluters, and are at significant risk of the effects of climate change (KE et al., 2018). The World Bank 'Climate Smart Healthcare' reports that only $15 \%$ of countries have a national climate change action plan in place which refers to health (Bouley, 2017). In 2014, it was estimated that the health carbon footprint of Ireland accounted for $6.7 \%$ of the national carbon footprint (Pichler, et al., 2019).

Healthcare facilities are also at the front lines of climate change, as hospitals, health centres and healthcare providers are first-line providers (Health Care Without Harm, 2016; Pichler et al., 2019; World Bank, 2017). It is in the best interest of healthcare facilities to make responsible decisions on the supply chain, energy use and transport services to ensure environmental and human (Health Care Without Harm, 2016). The progression of decarbonisation of the health sector will impact on the health of the public population through direct and indirect responses, including a decline in respiratory and cardiovascular diseases through reduced air pollution, lower infection risks through improved ventilation and improved safety for workers due to improved waste and energy management (Unit, 2012; World Bank, 2017).

The National Health Service (NHS) in the UK was one of the first countries to produce a national public report on the GHG emissions from the healthcare sector, which provided a national monitoring and evaluation system to demonstrate an $11 \%$ reduction in GHG emissions from 2007 to 2015 despite an $18 \%$ increase in health services activity during the timeframe (Unit, 2012).

\section{Findings}

Analysis of the qualitative interviews produced four master themes: The Working Environment of Hospitals, The Preparedness of the Healthcare Sector for Decarbonisation, Leadership and Finances (Figure 1) reflect what arose with participants on the opportunities and barriers of decarbonisation of the healthcare sector. The consensus view amongst all participants was that the focus within healthcare facilities needed to go beyond decarbonisation, and more consideration needed to be given to green and sustainable policies, in the context of issues relating to climate change more broadly.

\section{Working environment of hospitals}

The challenge of hospitals' working environments was identified as a key influence affecting any policies to introduce further decarbonisation within the sector. The working environment also influences the daily behaviour of staff, such

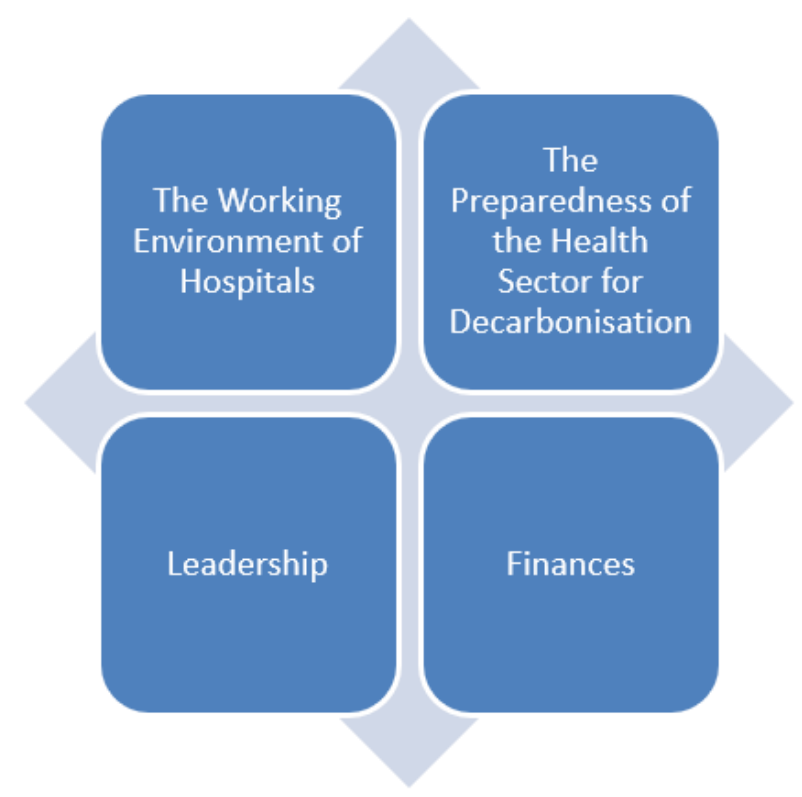

Figure 1. Master Themes Analysis

as their attitude towards energy management, policy-making within the institutions, and the role of the healthcare professional and administrative staff within the hospital sector.

Role of Staff and Healthcare Practitioners: The role of staff and healthcare practitioners was identified as both a key opportunity and barrier in relation to education, influence, and daily work behaviour of staff. With the large number of staff employed, it was noted by one participant that further education was needed to introduce behaviour changes around energy-saving measures; waste management and staff transport to work were also suggested. Health professionals were acknowledged by all participants as having a major role in their ability to "challenge health practice from the inside" along with their professional role of ensuring patient care. The importance of peer education was highlighted due to the challenge that an external individual may encounter through lack of an understanding into the culture, social dynamics and pressure associated with hospital systems.

Time pressures for clinicians and hospital staff were also recognised by respondents, along with other competing challenges within hospital working environments such as clinic work, emergency admissions and patient demands. The literature reviewed also revealed the complexity of managing clinicians and hospital staff due to the decision-making authority that occurs within the hospital environment (Edwards \& Saltman, 2017). The issue of staff being "timeshort" as a barrier.

“The people who do best on sustainability are those who have time to think about it.

If you don't have any time to think about it - if it literally is a one second additional task to put something into recycling bin rather than something next to you - it won't happen."

Transdisciplinary approach: A common thread amongst the participants was on teamwork within the hospital working 
environment which arose transdisciplinary work. According to participants, the establishment of 'Green Teams' in hospitals provides an opportunity to increase knowledge, work across disciplines, and improve and influence policies within hospitals.

A challenge highlighted by participants regarding hospital sectors' working environment related to the local politics and governance experienced in the area of sustainability. These issues include poor communication, barriers in implementing policies, lack of monitoring and evaluation of policies and resistance to change from management. As hospitals are complex adaptive systems, change is often dynamic which may result in hospitals acting as independent agents, in particular in Ireland, which has a public and private hospital sector.

\section{Preparedness of the healthcare sector for decarbonisation}

The preparedness of the healthcare sector for decarbonising and achieving carbon zero within the governance-guided timeframe was a dominant theme explored across all interviews. Respondents referred to energy efficiency, transport, waste and procurement as the main areas within the realm of achieving net zero carbon. They also highlighted the need for the mitigation and adaptation of the healthcare sector.

Mitigation and adaptation of healthcare sector: Building resilient healthcare systems involves developing long-term solutions to climate change. The World Bank Report recommends a framework of 'Climate-Smart Healthcare' (World Bank, 2017) to improve health systems by strengthening them through mitigation and adaptation, where programmatic responses are developed to address the burden of disease related to climate change, with heatwave plans and early warning systems. One participant highlighted the need to integrate mitigation and adaptation measures into one plan, rather than two separate concepts:

“..Don't just focus on decarbonisation, focus on (health) risk too. Decarbonisation is taking the carbon out of the system, but the health sector in particular is highly vulnerable to risk too, so how we plan for that risk and how we prepare for it and adapt to it."

Another participant reflected on the role of local policy building within the healthcare sector, and the challenge that lay ahead as "healthcare is very hard to adapt, it doesn't change overnight and therefore we need a plan." This participant spoke about drawing from the latest 'Climate Action Plan' (Department of Communications, 2019) to formulate a mandate examining the pathway towards decarbonisation through adaptation and flexibility to transform when faced with challenges and resilience -

\footnotetext{
"We are doing a lot of looking at climate mitigation but we have to build in resilience and we are going to have to build in climate adaptation. No matter what we do, the climate is going to change."
}

The World Health Organisation (WHO) defines a climate resilient healthcare as "one that is capable to anticipate, respond to, cope with, recover from, and adapt to climaterelated shocks and stress, so as to bring sustained improvements in population health, despite an unstable climate" (World Bank, 2017). Examples of resilience within the healthcare sector highlighted by participants included risk and disaster preparedness and planning, climate-related disease monitoring, flood barriers and back-up generators. The cobenefits of a prepared healthcare sector were also emphasised by participants through the improvement of air quality, improved energy savings and resource savings with the reuse of products and improved patient and staff health through active transport. One participant discussed their own experience of barriers including the need for technology improvement, political will, future investment and financial costs in scaling up adaptation and mitigation measures within hospitals in Ireland.

Transport: Active travel is recognised in the literature as a climate change mitigation measure with major co-benefits to health including reduced risk of diabetes, ischaemic heart disease, stroke and obesity (Haines, et al., 2006). The participants highlighted the benefits of increased walking and cycling as modes of active transport, and one participant described:

"You can either tell people to walk to work rather than
driving their cars because it will reduce their carbon
emissions or because it will get them fit and healthy.
They are more likely to do it because it makes them fit
and healthy rather than carbon emissions reason."

One of the barriers regarding transport is the accessibility and planning of hospitals close to public transport. Examples within the literature include reducing GHG emissions through home patient tele-monitoring, health worker advice over mobile phones and better management of pharmaceutical procurement and facility inputs (World Bank, 2017).

Energy: All of the participants spoke of the urgency to improve the energy efficiency within hospitals, which in turn would lead to further decarbonisation. Building improvements for hospitals may include measures to improve the thermal regulation of existing buildings, energy saving potential within IT equipment, lighting and operation of machinery and switching or retrofitting to carbon efficient heating and cooling technologies (World Bank, 2017). One participant expressed concern over the sustainability of the building structures of hospitals in their experience:

"Most of our hospitals are not efficient buildings, they
don’t have efficient heating building systems. We are
building hospitals, which will be powered by gas, which
is not going to be sustainable in long term. Even in our
new hospitals we should be building buildings which
are zero carbon, and ready for the future."

\section{Leadership}

One of the emergent themes portrayed throughout the five sectors was around the value and role of successful initiatives such as the role of a 'Green Champion', a multidisciplinary 'Green Team' or corporate recognition within the healthcare sector and also within the wider Irish society.

Successful 'Green' Initiatives within the workspace: All of the participants highlighted initiatives within their sectors 
which they believed successful in their workplace, which revolved around the theme of 'Green Team / Champion Role'. One example was a 'Green Team' where one representative represented each discipline, incorporating the planetary health principle of transdisciplinary teamwork. This was successful due to the cost savings for the workplace as identified through the monitoring and evaluations carried out.

Another suggestion for future initiatives within the hospital sector was a role of a "Green Representative", who would be responsible for the ongoing monitoring and evaluation of waste management, energy savings and ensuring set targets from local and national policies within hospitals:

"Every team has one consultant on it leading the team or - it doesn't have to be consultant - it could be physio or clinicians (..) having one person per department or team leading it (the sustainable policy)"

In the context of larger hospital initiatives driving change, one respondent referred to the need to enhance and recognise the value of monitoring and evaluating targets. According to the Lancet Countdown report, there is currently no systematic global standard for monitoring GHG of the health care sectors (indicator 3.9) (Watts et al., 2018). While the NHS in the UK has reported annual national emissions (Unit, 2012; Watts et al., 2018), the estimates elsewhere are rarely standardised across sites. The participants highlighted the lack of standardised monitoring as an issue.

Interest as a citizen in Irish society: The role of a global citizen advocate for decarbonisation within hospitals is supported by the literature from exemplary groups such as Clinicians for Planetary Health, World Medical Association 'My Green Doctor', Alliance of Nurses for Healthy Environment (Alliance, 2019); One interviewee suggested the role of advocacy as a healthcare professional may be an opportunity to influence policy-making within the healthcare sector as they are well placed to advocate for greener policies. It was also acknowledged by participants that the current societal values had an influence on staff of the workplace -

"the "wave" of interest has developed and climate change is very much in the news and in people's minds as well."

These societal values were challenged by another participant, who commented on the lack of knowledge and awareness society has around decarbonisation within the workplace -

“Decarbonisation is not on people's agendas at all and that is something that society as a whole needs to reflect on. Globally not just in this country - just that level of awareness on decarbonisation. That in itself, the lack of awareness is huge, especially when you follow these events in the media."

A more sustainable, healthier society through decarbonisation was a suggestion from all the participants. The health co-benefits of decarbonisation documented in the literature occur through three main pathways of mitigation, adaptation and sustainable development as highlighted by the IPCC report (IPCC, 2018).

\section{Finances}

Cost savings and financing of sustainability programmes were dominant themes expressed by all the participants. Participants highlighted the importance of investment towards a carbon zero Ireland, with a particular emphasis on the cost savings within the health sector. The long-term gain from investment was highlighted throughout the interviews. Investment in scaling up finance for climate-resilient health systems resonated in the literature, with one of the recommendations from the Lancet Countdown report in 2018 highlighting that climate finance for mitigation and adaptation remains below the commitment within the Paris Agreement, with only $3.8 \%$ of the funding in 2017 allocated for health adaptation (indicator 2.8) (Horowitz, 2016; Watts et al., 2018).

The NHS marginal abatement cost curve has shown several returns in health-related carbon interventions in fewer than five years (World Bank, 2017), which had the dual effect of saving money and reducing the carbon footprint. Examples of this include combining heat and power instalments in trusts, improving heating and lighting controls, improving energy efficiency lighting and running energy awareness campaigns. While the cost of retro fitting many hospitals and the need for initial high capital investment were raised as barriers from participants, acknowledging that finding the capital investment to develop a climate-resilient healthcare system is necessary in Ireland.

\section{DISCUSSION}

Within the $\mathrm{PH}$ Principles and framework lies the acknowledgement that environmental stewardship and sustainability can directly benefit human health (Stone, et al., 2018). It provides a cohesive method of examining the complex relationships between human modification of the environment and human health outcomes to strengthen the case for urgent policy action and governance through a systems-thinking approach (Perspectives, 2017; Whitmee et al., 2015).

Ireland is shaped by the political context of the EU and international climate commitments. In 2015, the first Climate Action and Low Carbon Development Act (2015) was passed by Parliament in Ireland to ensure the transition to a low carbon, environmentally-sustainable society by 2050, as outlined in international guidelines for Paris Agreement (Horowitz, 2016). No targets were set for specific GHG reductions in Ireland in the legislation at the time.

Kingdon (1984) suggests that policy change comes about when three streams flow independently until a crossing of a 'window of opportunity' when they collide and policy is formed, with the issue rising to the top of the policy agenda. The 'problem stream' represents the indicators that an issue exists (climate change), the 'political stream' comprises factors which influence policies (growing international awareness of climate change), and the 'policy stream' comprises of a range of solutions that exist (initiation of a Citizen Assembly). Within the climate agenda context in 
Table 2. Cross-Cutting Principles for Planetary Health Education (Stone et al., 2018)

\begin{tabular}{ccc}
\hline $\begin{array}{c}\text { 1. A Planetary } \\
\text { Health Lens }\end{array}$ & 5. Communication & 9. Governance \\
\hline $\begin{array}{c}\text { 2. Urgency and } \\
\text { Scale }\end{array}$ & $\begin{array}{c}\text { 6. Systems Thinking and } \\
\text { Transdisciplinary } \\
\text { Collaborations }\end{array}$ & $\begin{array}{c}\text { 10. Unintended } \\
\text { Consequences }\end{array}$ \\
\hline 3. Policy & 7. Inequality \& Inequity & 11. Global Citizenship \\
\hline $\begin{array}{c}\text { 4. Organising and } \\
\text { Movement Building }\end{array}$ & 8. Bias & $\begin{array}{c}\text { 12. Historical and } \\
\text { Cultural Values }\end{array}$ \\
\hline
\end{tabular}

Ireland, these streams collided at the time of the Citizen Assembly.

On 18 April 2018 the Citizen Assembly Report was published and included thirteen recommendations (Assembly, 2018). On 29 March 2019, the Joint Committee on Climate Change published a further Cross-Party Report which resulted in the final 'Climate Action Plan', (Department of Communications, 2019) published on 17 June 2019. This report highlights the goal to decarbonise the public and private sectors in order to achieve a net zero carbon energy systems for Irish society to ensure the sustainability and resilience of communities (Department of Communications, 2019).

The grass-roots partnership approach to policy-making through the Citizen Assembly is pivotal and unique in national decision-making and policy-making in relation to key social issues in the Republic of Ireland. The participative process involved in the Assembly on Climate Change reflects and encompasses several of the planetary health principles as outlined by Myers (2018) (Table 2) (Stone et al., 2018) including the principles of organising and building movement, systems-thinking and transdisciplinary collaborations, governance, policy and global citizenship. This framework provides an opportunity to achieve long-lasting positive changes on a multi-sectorial interdisciplinary level, both locally and globally.

\section{A Planetary Health Lens (Principle 1) \& Urgency and Scale (Principle 2)}

These principles focus on the linkages, cause-effect relationships and feedback-loops between environmental change and human health (Stone et al., 2018) which is explored within the theme of preparedness of the healthcare sector, through efficient energy use in hospitals considering the heating, water use, ventilation and energy management (World Bank, 2017). Opportunities for improving decarbonisation in the health sector highlighted by the participants in this research report include the longer term cost savings for the health sector and tax payers, the health cobenefits and improving transport links which occur when energy-saving measures are implemented.

The PH principle of urgency and scale is explored through the opportunities highlighted by participants through the monitoring and evaluation of targets, and the need to scale up financial initiatives to support decarbonisation measures. In Ireland, the Public Sector Energy Efficiency Strategy planned a $33 \%$ reduction in energy use by 2020 target, with the current public sector bodies target reaching 24\% in 2019 (Ireland, 2017). No update has been reported to the public on whether progress has been made on reaching targets since 2017 (Ireland, 2017).

\section{Policy (Principle 3) \& Governance (Principle 9)}

These principles explore the applications of research to strengthen and improve evidence gaps and policy action. Within the recommendations of the 'Report of the Joint Committee on Climate Action Climate Change: A Cross - Party Consensus for Action' (pg. 85 9.5.2), the Committee states that they did not get an opportunity to examine decarbonisation of the health sector, in particular the public hospitals (Change, 2019).

The European Union (EU) elections of May 2019 resulted in an increase in support for the Green Party, coined by the international media as 'The Green Wave' (Mallet, 2019). As highlighted, initiatives such as 'Big Switch Off' and 'Optimising Power@Work' campaigns within the Health Service Executive (HSE) have been successful during pilot projects (Work, 2018), which if implemented within hospitals could result in significant cost savings. It was also suggested to continue governance of the targets of GHG emissions.

Organising and Movement Building (Principle 4), Communication (Principle 5) \& Systems Thinking and Transdisciplinary Collaborations (Principle 6)

These PH principles were explored within the theme of the Working Environment of Hospitals. It is recognised in the literature that developing and communicating shared understandings and actions between researchers, communities and policy-makers can often be a complex socialecological system (Ensor and Harvey, 2015). Adaptation measures of the healthcare sector require new thinking of building social systems and adapting the working environment (Ensor and Harvey, 2015).

Green Teams were explored as an example to encompass the planetary health principles of transdisciplinary collaborations, with representatives from engineering, medicine, nursing, administrative, finance and maintenance staff. Healthcare Without Harm also offer an opportunity for healthcare practitioners to mobilise healthcare institutions around the world to play a leadership role in addressing climate change (Health Care Without Harm, 2016).

Inequality \& Inequity (Principle 7), Bias (Principle 8) \& Unintended Consequences (Principle 10)

The $\mathrm{PH}$ principles of inequality and inequity, bias and unintended consequences involves a critical analysis of the national and international dynamics at play, including the current political climate in which the context of this health policy report is set. Discussions remained underway for a UK Brexit departure from the EU in October 2019 at time of study, resulting in unintended knock-on health impacts and environmental changes of governance in Ireland, UK and internationally to the changing unstable political sphere.

Global Citizenship (Principle 11) \& Historical and Cultural Values (Principle 12)

The PH principle of global citizenship explores the identity of individuals who see themselves as part of an international community (Stone et al., 2018). The sub-theme of an 
individual being connected to a local, national and an international community emerged within the results, with organisations of clinicians and citizens advocating for their local and global communities.

This theme explores how the past can solve problems of the present through the political context in Ireland of the Citizens Assembly, established by the Irish Parliament (the Dáil) in July 2016 as a structured forum to allow citizen involvement in political decision-making. The Assembly consists of a Chairperson and 99 citizens who represent a variety and diversity of ages and backgrounds within the Republic of Ireland. The process of Citizens' Assemblies in Ireland has led to recommendations for policy changes within the Dáil, for example, the holding of the Same - Sex Marriage Referendum in 2015 (Information, 2018).

\section{Limitations of Methodology}

The data interview of five expert stakeholders is qualitative and therefore describes concepts of their own experiences of opportunities and challenges within their area of expertise and the healthcare sector. A small number of interviews were conducted due to time constraints. However, deep understanding of each respondents' insights and experiences generate sufficient data for the purpose of health policy report.

A limitation of the study is that it would have been beneficial to include a financial or economic expert stakeholder for their views on decarbonisation of the healthcare sector from a cost perspective. The researcher reached out to the financial sector within the HSE, but did not receive a response. Nevertheless, the interviewees for this research identified finance and cost a cross-cutting issue experienced by different departments.

It is possible that some literature was not identified, that may have been relevant to this report. This may have been overlooked due to the fact that grey literature is not always systematically available through databases.

\section{RECOMMENDATIONS}

Recommendations may be adopted by the offices of the Minister for Communications, Climate Action and Environment and the Minister of Health in the Parliament of Ireland (the Dáil) to apply to the HSE. While acknowledging the limitations of semi-structured interviews used as a tool to measure policy implementation, it is possible to derive conclusions and identify a number of recommendations including the need for further research within the area of hospitals.

Transdisciplinary Approach and Collaboration within the Health System, from a Local to National Level

Transdisciplinary governance through fostering relationships across government sectors, strengthening institutions at multiple levels from 'bottom up' and 'topdown' approaches, and ensuring inter-governmental policies are implemented across each hospital to ensure carbonneutral targets within the health sector. It is also recommended that the government create collaborations and continue to build partnerships within the HSE and the transport sector, financial institutions, environmental agencies, climate information services to carry out the 'Climate Action Plan' to prepare for health-related climate hazards.

\section{Decision Makers Must Ensure Governance through Further Monitoring and Evaluation of the Carbon Footprint of the Health Sector}

Providing a published annual update for the public on the levels of GHG emissions would enable further action through governance on decarbonisation. While acknowledging the Sustainable Energy Authority of Ireland (SEAI) have monitored GHG emissions, the results should continue to be presented and published annually on the waste, water, procurement and energy management within each hospital. As the NHS has demonstrated, providing annual monitoring and evaluation figures led to further measures to decrease the carbon footprint, despite an increase in activity and use of the health services.

\section{Strengthen and Broaden Interventions within the Hospital Sector including Financial Scale up of Successful Pilot Initiatives within Regional Hospitals}

Leveraging the impact of local and national sustainability teams was highlighted, along with further scale up of initiatives previously successful as pilot projects. Investment is required by the health sector to scale successful pilot projects, focused on energy efficiency, local transport systems, safe water provision, procurement and the purchasing of local and sustainable food.

Promote Leadership of Health Professional Roles within the Field of Environment and Human Health

Clinicians and health professionals were highlighted within this study as having an ability to influence policy at local and national levels. Healthcare professionals should be encouraged to become leaders in climate change and act as global citizens to advocate for the impacts of climate change as a public health issue, peer educate and continue to be supported to advocate for change within the healthcare industry.

Incentivising Funding for Improvement and Investment in Low-carbon Technology across Sectors

One of the barriers highlighted within this report was the investment required in scaling up low - carbon technology to build health resilient sectors. More efficient energy generation will be required to ensure a rapid transition from fossil fuels to renewable energy technologies while minimising the potential electricity grid instabilities and environmental burdens.

Increasing Efforts to Ensure Long Term Capital Investments are Made within the Healthcare Sector for Preparedness in Face of Climate Changes in the Near Future

A further recommendation is the consideration of allocation of 'ring-fenced' funding for climate adaptation and mitigation within the health sector to avoid competing priorities. Further consideration into funding and investment may be explored from development institutions, 
philanthropists, industries and institutions for climate financing mitigation and adaptation of healthcare services.

\section{Strong Political Action and Will}

Strong leadership and governance will need to be shown by the Irish Government to ensure action on the mandate of the 'Climate Action Plan.' The co-benefits of climate - smart healthcare will strengthen the healthcare sector and communities by ensuring access to clean transport, safe water, clean energy and waste disposal, along with preparing for unknown health-related climate hazards.

\section{CONCLUSION}

The grass-roots partnership approach to policy-making in Ireland of the role of Citizen Assembly is pivotal in national decision-making and policy-making in relation to key social issues. The participative process involved in the Citizen Assembly on Climate Change (Assembly, 2018) reflects and encompasses several of the planetary health principles (Stone, Myers, D, \& Group, 2018) including organising and building movement, systems-thinking and transdisciplinary collaborations, governance, policy and global citizenship. This framework provides an opportunity to achieve long-lasting positive changes on a multi-sectorial interdisciplinary level, both locally and globally.

The Lancet Commission on Climate and Health appealed to international governments to act on the "greatest global health opportunity of the $21^{\text {st }}$ century" (Costello A. , et al., 2009). The Irish health sector is encouraged to lead by example in a transdisciplinary approach working from the Planetary Health principles (Stone, Myers, D, \& Group, 2018) on acting on climate change by ensuring hospitals are centres of excellence. This can be achieved by providing both direct provision of care for patients' health, and also ensuring the health sector acts on reducing health systems' contribution to GHG emissions.

\section{REFERENCES}

Agency, E. P. (2019). What are Irelands Greenhouse Gases. Available at: https://www.epa.ie/climate/communicating climatescience/whatisclimatechange/whatareirelandsgree nhousegasemissionslike/ (Accessed: 29 August 2019).

Alliance, P. H. (2019). Clinicians for Planetary Health. (Online) Available at: https:/www.planetaryhealthalliance.org/ clinicians-for-planetary-health\#: :text=The\%20Clinicians \%20for\%20Planetary\%20Health,healthcare\%20for\%20indi viduals\%20and\%20communities (Accessed: 20 August 2019).

Assembly, T. C. (2018). Third Report and Recommendations of the Citizen's Assembly - How the State can Make Ireland a Leader in Tackling Climate Change, Dublin, Ireland: s.n.

Burck, J., et al. (2019). Climate Change Performance Index Results 2019, s.1.: Germanwatch, New Climate Institute, Climate Action Network.
Change, J. C. o. C. (2019). Report of the Joint Committee on Climate Action: Climate Change: A Cross-Party Consensus for Action, Dublin: House of Oireachtas.

Charlesworth, K. E., Stewart, G. J. and Sainsbury, P. (2018). Addressing the carbon footprint of health organisations: eight lessons for implementation. Public Health Res Pract, 28(4), 28. https://doi.org/10.17061/phrp2841830

Costello, A., et al. (2009). Managing the health effects of climate change: Lancet and University College London Institute for Global Health Commission. Lancet, 373(9676), 1693-1733.

Costello, A., et al. (2009). Managing the health effects of climate change: Lancet and University College London Institute for Global Health Commission. Lancet. https://doi.org/10.1016/S0140-6736(09)60935-1

Cunningham, P. (2019). Ireland becomes second country to declare climate emergency, Dublin: RTE.

Department of Communications, C. A. a. E. I. (2019). Climate Action Plan, s.l. Available at: https://www.dccae.gov.ie/enie/climate-action/publications/Pages/Climate-ActionPlan.aspx

Desmond, M., O’Brien, P. and McGovern, F. (2014). A Summary of the State of Knowledge on Climate Change Impacts for Ireland, s.l.: Environmental Protection Agency.

Edwards, N. and Saltman, R. B. (2017). Re-thinking barriers to organizational change in public hospitals. Israel Journal of Health Policy Research, 6(16). https://doi.org/10.1186/ s13584-017-0133-8

Ensor, J. and Harvey, B. (2015). Social learning and climate change adaptation: evidence for international development practice. Wires Climate Change. https://doi.org/10.1002/wcc.348

Foster, A., Cole, J., Farlow, A. and Petrikova, I. (2018). Planetary Health Ethics: Beyond First Principles. Challenges, 10(1). https://doi.org/10.3390/challe10010014

Guniea, A. (2019). The U.K. has officially declared a climate 'emergency', New York: Time.

Haines, A., Kovatsa, R., Campbell-Lendrumb, D. and Corvalan, C. (2006). Climate change and human health: Impacts, vulnerability and public health. Public Health, 120(7), 585596. https://doi.org/10.1016/j.puhe.2006.01.002

Health Care Without Harm. (2016). Reducing Healthcare's Climate Footprint - Opportunities for European Hospitals \& Health Systems, s.l.: HCWH.

Horowitz, C. A. (2016). Paris Agreement. Paris: International Legal Materials. Cambridge University Press. https://doi.org/10.1017/S0020782900004253

Information, C. (2018). Available at: https://www.citizensinformation.ie/en/government_in_ire land/irish_constitution_1/constitutional_convention.html (Accessed: 30 August 2019).

IPCC. (2018). Global Warming of $1.5^{\circ} \mathrm{C}$. An IPCC Special Report on the impacts of global warming of $1.5^{\circ} \mathrm{C}$ above preindustrial levels and, s.l.: IPCC. 
IPCC. (2019). IPCC, 2019: Summary for Policymakers. In: Climate Change and Land: an IPCC special report on climate change, desertification, land degradation, sustainable land management, food security, and greenhouse gas fluxes in terrestrial ecosystems, s.1.: IPCC.

Ireland, S. E. A. (2017). Public Annual Report SEAI. (Online) Available at: https://psmr.seai.ie/Reports/PublicAnnual ReportForPublic? customerId=233 \&query=undefined (Accessed 0308 2019).

Kelly de Bruin, A. M. Y. (2018). The economic and environmental impacts of increasing the Irish carbon tax, Dublin: ESRI Research Series No. 79. https://doi.org/10.26504/rs79

Kingdon, J. (1984). Agendas, alternatives and public policies. Boston: s.n.

Mallet, V. (2019). European green wave pushes environment to top of political agenda, s.l.: Financial Times.

Masli, et al. (2015). Health and climate change: policy responses to protect public health. Lancet, 386(10006), 1861-1914. https://doi.org/10.1016/S0140-6736(15)608546

Naderifar, M., Hamideh, G. and Ghaljaei, F. (2017). Snowball Sampling: A Purposeful Method of Sampling in Qualitative Research. Strides in Development of Medical Education, 14(3), e67670. https://doi.org/10.5812/sdme.67670

Perspectives, P. (2017). Global Policy Opportunities for Planetary Health, s.l.: s.n.

Pichler, P.-P., Jaccard, I. S., Weisz, U. and Weisz, H. (2019). International comparison of health care carbon footprints. Environ. Res. Lett., 14. https://doi.org/10.1088/17489326/ab19e1

Stone, S. B., Myers, S. S., D, C. and Group, P. H. E. B. (2018). Cross-cutting principles for planetary health education. The Lancet. Planetary health, 2(5), 192-193. https://doi.org/10.1016/S2542-5196(18)30022-6
Tomson, C. (2015). Hospital infrastructure reducing the carbon footprint of hospital-based care. Future Hospital Journal, 2(1), 57-62. https://doi.org/10.7861/futurehosp.15.016

Union, E. (2016). Regulation (EU) 2016/679 of the European Parliament and of the Council.

Unit, N. S. (2012). Sustainability in the NHS Health Check.

Unit, N. S. D. (2012). NHS Carbon Footprint. Available at: https://www.sduhealth.org.uk/policystrategy/reporting/nhs-carbon-footprint.aspx (Accessed: 20 August 2019).

Watts, N., et al. (2018). The 2018 report of the Lancet Countdown on health and climate change: shaping the health of nations for centuries to come. Lancet, 392(1013), 2479-2571.

Whitmee, S., Haines, A., Beyrer, C. and Boltz, F. (2015). Safeguarding human health in the Anthropocene epoch: report of The Rockefeller Foundation-Lancet Commission on planetary health. Lancet, 386(10007), 1973-2028. https://doi.org/10.1016/S0140-6736(15)60901-1

Will Steffen, P. J. C. J. R. M. (2007). The Anthropocene: Are Humans Now Overwhelming the Great Forces of Nature. AMBIO: A J. of the Human Environment, 36(8), 614-621. https://doi.org/10.1579/0044-7447(2007)36[614:TAAHNO] 2.0.CO;2

Work, O. P. a. (2018). Big Switch Off Winners. Available at: http://www.opw-energy.ie/currentfeatures/big-switchoff-winners/ (Accessed: 20 August 2019).

World Bank. (2017). Climate-Smart Healthcare - Low Carbon and Resiliance Strategies for Health Sector, Washington: The World Bank Group.

World Health Organization. (2018). Health benefits far outweigh the costs of meeting climate change goals. Available at: https://www.who.int/news-room/detail/0512-2018-health-benefits-far-outweigh-the-costs-ofmeeting-climate-change-goals (Accessed: 31 July 2019). 